OPEN ACCESS

Edited by:

Omry Koren,

Bar-llan University, Israel

Reviewed by:

Uri Gophna

Tel Aviv University, Israel

Michael Müller,

University of East Anglia,

United Kingdom

Donovan P. German,

University of California, Irvine,

United States

*Correspondence:

Yuheng Luo

luoluo212@126.com

${ }^{\dagger}$ These authors have contributed equally to this work.

Specialty section: This article was submitted to

Microbial Symbioses,

a section of the journal

Frontiers in Microbiology

Received: 09 November 2016 Accepted: 15 May 2017

Published: 30 May 2017

Citation:

Luo Y, Zhang L, Li H, Smidt H, Wright A-DG, Zhang $K$, Ding $X$,

Zeng $Q$, Bai S, Wang J, Li J,

Zheng P, Tian G, Cai J and Chen D

(2017) Different Types of Dietary

Fibers Trigger Specific Alterations

in Composition and Predicted Functions of Colonic Bacterial

Communities in BALB/C Mice.

Front. Microbiol. 8:966.

doi: 10.3389/fmicb.2017.00966

\section{Different Types of Dietary Fibers Trigger Specific Alterations in Composition and Predicted Functions of Colonic Bacterial Communities in BALB/c Mice}

Yuheng Luo ${ }^{1 *}$, Ling Zhang ${ }^{1+}$, Hua Lit, Hauke Smidt', André-Denis G. Wright ${ }^{3}$, Keying Zhang ${ }^{1}$, Xuemei Ding ${ }^{1}$, Qiufeng Zeng ${ }^{1}$, Shiping Bai ${ }^{1}$, Jianping Wang ${ }^{1}$, Jian Li', Ping Zheng ${ }^{1}$, Gang Tian ${ }^{1}$, Jingyi Cai' ${ }^{1}$ and Daiwen Chen ${ }^{1}$

\footnotetext{
'Key Laboratory for Animal Disease-Resistance Nutrition of China, Ministry of Education, Animal Nutrition Institute, Sichuan Agricultural University, Chengdu, China, ${ }^{2}$ Laboratory of Microbiology, Wageningen University, Wageningen, Netherlands,

${ }^{3}$ School of Animal and Comparative Biomedical Sciences, University of Arizona, Tucson, AZ, United States
}

Soluble dietary fibers (SDF) are fermented more than insoluble dietary fibers (IDF), but their effect on colonic bacterial community structure and function remains unclear. Thus, bacterial community composition and function in the colon of BALB/c mice $(n=7)$ fed with a high level (approximately $20 \%$ ) of typical SDF, oat-derived $\beta$-glucan (G), microcrystalline cellulose (M) as IDF, or their mixture (GM), were compared. Mice in group $\mathrm{G}$ showed a lowest average feed intake $(p<0.05)$ but no change on the average body weight gain $(p>0.05)$ compared to other groups, which may be associated with the highest concentration of colonic propionate $(p<0.05)$ in these mice. The bacterial $\alpha$-diversity of group $G$ was significantly lower than other groups $(p<0.01)$. In group $\mathrm{G}$, the relative abundance of bacteria belonging to the phylum Bacteroidetes was significantly increased, whereas bacteria from the phylum Firmicutes were significantly decreased $(p<0.01)$. The core bacteria for different treatments showed distinct differences. Bacteroides, Dehalobacterium, and Prevotella, including known acetogens and carbohydrate fermenting organisms, were significantly increased in relative abundance in group G. In contrast, Adlercreutzia, Odoribacter, and Coprococcus were significantly more abundant in group M, whereas Oscillospira, Desulfovibrio, and Ruminoccaceae, typical hydrogenotrophs equipped with multiple carbohydrate active enzymes, were remarkably enriched in group GM $(p<0.05)$. The relative abundance of bacteria from the three classes of Proteobacteria, Betaproteobacteria, Gammaproteobacteria (including Enterobacteriaceae) and Deltaproteobacteria, were significantly more abundant in group $G$, indicating a higher ratio of conditional pathogenic bacteria in mice fed dietary $\beta$-glucan in current study. The predicted colonic microbial function showed an enrichment of "Energy metabolism" and "Carbohydrate metabolism" pathways in mice from group $\mathrm{G}$ and $\mathrm{M}$, suggesting that the altered bacterial community in the colon of mice with the two dietary fibers probably resulted in a more 
efficient degradation of dietary polysaccharides. Our result suggests that the influence of dietary $\beta$-glucan (SDF) on colonic bacterial community of mice was more extensively than MCC (IDF). Co-supplementation of the two fibers may help to increase the bacterial diversity and reduce the conditional pathogens in the colon of mice.

Keywords: dietary fibers, colonic bacterial community, $16 \mathrm{~S}$ high throughput sequencing, PICRUSt predicted functions, BALB/c mice

\section{INTRODUCTION}

The microbiota in the hindgut of humans and non-ruminant animals is highly complex and comprises many thousands of bacterial species (Arumugam et al., 2011; Kau et al., 2011). The number of microbial gene copies is approximately 100 times more than that of the host (Bäckhed et al., 2004), and thus, the gut microbiota has been referred to as another "organ" of the animal body (O'Hara and Shanahan, 2006). The composition of the gut microbial community can be strongly affected by many factors such as diet (Walker et al., 2011), age (Yatsunenko et al., 2012), antibiotic administration (Relman, 2012), host genotype (Walker et al., 2011) and immunological response (Hooper et al., 2012), or infection with pathogenic organisms (Kau et al., 2011). The change of dietary components can quickly lead to a change in the composition of the microbiota (Flint et al., 2012). Of those dietary components, dietary fiber has been proven to significantly alter the composition of the intestinal microbiota (Lattimer and Haub, 2010).

There are up to 1,000 different species of bacteria that reside in the colon with microbial communities comprising approximately $10^{11}-10^{12}$ cells/g of contents (Gibson et al., 2010). The colonic environment is favorable for bacterial growth due to its slow transit time, readily available nutrients, and favorable $p H$ (Cummings and Macfarlane, 1991). Dietary fibers that escape the digestion in the small intestine are passing largely intact into the colon where they increase viscosity and bulking of the fecal matter (Lattimer and Haub, 2010) and can be degraded by microbiota in the hindgut of animals (El Aidy et al., 2013). For example, a recent study showed that ingestion of a diet low in fermentable carbohydrates resulted in lower abundance of Firmicutes, including the families Clostridiaceae, Lachnospiraceae, and Ruminococcaceae (Belcheva et al., 2014). 16S rRNA gene sequence analysis revealed that the fecal microbiota from rural African children consuming a plant-based agrarian diet rich in fruit and legume fiber (12.6 g/14.2 g total fiber) was enriched with bacteria belonging to the phyla Actinobacteria and Bacteroidetes, with unique bacteria belonging to the genera Prevotella and Xylanibacter, but had lower levels of Firmicutes compared to European (EU) children. Whereas, pathobionts belonging to the genera Shigella and Escherichia were more abundant in EU samples (De Filippo et al., 2010). Opposite results were also reported in another study, where a diet low in fat and high in dietary fiber was associated with increased relative abundance of bacteria belonging to the phylum Firmicutes, whereas a diet high in fat was associated with increased relative abundance of members of the Actinobacteria and genus Bacteroides (Wu et al., 2011).
In humanized gnotobiotic mice, consumption of a Western diet was associated with an increase in the relative abundance of Firmicutes, the Bacilli (mainly Enterococcus) and a decrease in the proportional representation of members of the Bacteroidetes (Turnbaugh et al., 2009). In another study, $1110^{-/-}$mice, fed a low-fat diet promoted more Firmicutes bacteria (Devkota et al., 2012). In humans and CEABAC10 mice, the change of dietary composition had different influence on the abundance of bacteria belonging to the phyla Firmicutes and Bacteroidetes (David et al., 2014; Martinez-Medina et al., 2014). Taken together, these results reinforce that ingestion of dietary fiber alters the bacterial community in the hindgut of non-ruminant animals.

Several recent studies revealed the effects of different fibers on colonic microbiota composition of host. Wheat bran promoted the enrichment of butyrate-producing bacteria releasing ferulic acid in the colon of human in vitro (Duncan et al., 2016). In dietinduced obese C57BL/6J mice, non-digestible fructans reduced their fecal bacterial diversity and increased the relative abundance of Actinobacteria as well as Verrucomicrobia compared with cellulose (Liu et al., 2016). Another study in mice fed a high-fat diet showed that the supplement of maize-derived non-digestible feruloylated oligo- and polysaccharides increased the abundance of Blautia and Akkermansia in the cecum of some mice, which was associated with reductions in body and adipose tissue weights (Yang et al., 2016). The results suggest a relationship between the type of dietary fiber and the microbial community in the hindgut of human and mice. Although dietary fiber has been classified according to its solubility in an attempt to relate physiological effects to chemical types of fiber (Marlett et al., 2002), it is recognized that additional properties of fiber, such as viscosity and fermentability, may be more important characteristics in terms of physiological benefits (Slavin et al., 2009). Generally, it is recognized that soluble dietary fibers (SDF) are fermented more and have a higher viscosity than insoluble dietary fibers (IDF), although not all SDF are viscous and some IDF may be well fermented (Slavin, 2013). However, very little is known about the in vivo fermentation of the two types of fibers by the colonic bacteria. Whether there are bacteria that specifically utilize SDF and IDF, the influence of single or mixed types of dietary fiber, and the impact of different types of dietary fibers on colonic microbial functions, host health, and metabolism still remain unclear.

In the present study, oat-derived $\beta$-glucan (Andersson et al., 2004) as a typical fermentable SDF fiber, and microcrystalline cellulose (MCC) (Pandey, 1999) as a typical difficult to degrade IDF (Slavin, 2013), were selected as supplementary dietary fibers. 
Oat $\beta$-glucan is recognized as a linear polymer of $\mathrm{D}$-glucose bonded by $\beta-(1 \rightarrow 4)$ and $\beta-(1 \rightarrow 3)$ glucosidic linkage (Wang and Ellis, 2014), which is different from the D-glucose units of cellulose linearly chained via $\beta-1,4$ glycosidic linkages (Bauer et al., 1999). The exposed reducing ends of oat $\beta$-glucan molecular probably makes it soluble rather than cellulose which doesn't have the available reducing ends. Fibers were fed to $\mathrm{BALB} / \mathrm{c}$ mice for a period of 21 days, and colonic bacterial community composition and derived functions were evaluated. Notablely, unlike human or most of the nonruminants, mice are coprophagic animals, which may influence the digestion of nutrients (Jensen et al., 2013). Thus although the results shown here may not be directly applicable to other animals, they still could potentially provide some new leads toward understanding the microbial groups specifically utilizing IDF and SDF in the hindgut of non-ruminant animals and humans.

\section{MATERIALS AND METHODS}

All experimental procedures and animal care were performed in accordance with the Guide for the Care and Use of Laboratory Animals prepared by the Institutional Animal Care and Use Committee of Sichuan Agricultural University, and all animal protocols were approved by the Animal Care and Use Committee of Sichuan Agricultural University under permit number DKYB20131704.

\section{Experimental Design and Sample Collection}

A total of 28 healthy male BALB/c mice at 8 weeks old were selected as experimental animals, and assigned randomly to four experimental diets based on their body weight (BW). Mice in the control group were fed a standard mouse diet formulated to meet the nutrient requirements of the American Institute of Nutrition Rodent Diets (AIN-93). Mice in the remaining three groups were fed either a diet with 28\% (of total dietary ingredients) $\beta$-glucan from oat (Arrhenatherum elatius) (group G), 20\% MCC (group M), and a mixture of $\beta$-glucan (14\%) and MCC (10\%) (group GM), respectively, based on the control diet. The concentrations of principal nutrients, such as lipid, protein, amino acids, minerals and vitamins of the four treatments were kept equivalent to a maximum limit (Supplementary Table S1). The $\beta$-glucan and MCC were supplied by Ci Yuan Biotechnology Co., Ltd (Shanxi, China), and the measured concentrations of $\beta$-glucan and MCC in raw ingredients were 71.2 and $98.5 \%$, respectively. The particle size of oat- $\beta$-glucan and MCC used in current study is 108 and $150 \mu \mathrm{m}$, respectively. Final calculated concentrations of $\beta$-glucan in the diet of group G and GM were 19.6 and $9.8 \%$, respectively. The calculated concentrations of MCC in the diet of groups M and GM were 19.8 and 9.9\%, respectively. The concentration of $\mathrm{SDF}$ in the diets for the control, G, M, and GM groups were measured as 1.5, 10.1, 1.6 , and 2.5 ( $\mathrm{g} / 100 \mathrm{~g}$ diet), respectively, while the concentration of IDF for the four groups was 14.3, 10.9, 30.3, and 24.6 ( $\mathrm{g} / 100 \mathrm{~g}$ diet), respectively. The initial BW of the mice in the four groups (seven mice for each group, one cage for each individual) was $17.90 \pm 1.07$ (control), $18.20 \pm 0.88$ (group $\mathrm{G}$ ), $17.60 \pm 1.04$ (group $\mathrm{M}$ ) and17.40 \pm 1.15 (group GM) $(p=0.51)$, respectively. The degree of purity of $\beta$-glucan and MCC and the concentrations of SDF and IDF in the diets were measured by Scist Testing Institute Co., Ltd (Qingdao, China). The concentration of $\beta$-glucan in feed sample was detected using congo red staining method. Congo red solution was prepared by dissolving $0.200 \mathrm{~g}$ of congo red into $0.1 \mathrm{~mol} / \mathrm{L}$ phosphate buffer ( $p H$ 8.0) to produce $200 \mathrm{~mL}$. Precisely, $0.0100 \mathrm{~g}$ standard $\beta$-glucan was weighed and dissolved into deionized water at $70^{\circ} \mathrm{C}$. The solution was diluted to a concentration of $100 \mu \mathrm{g} / \mathrm{mL}$ for standard curve. Different volumes of standard solution, 0.0, 0.2, $0.6,0.8$, and $1.0 \mathrm{~mL}$, were added into $10-\mathrm{mL}$ colorimetric tubes and then deionized water was added into each tube to $2.0 \mathrm{~mL}$, respectively. A volume of $4.0 \mathrm{~mL}$ cango red solution was then added into each tube, mixed and reacted at $20^{\circ} \mathrm{C}$ for $30 \mathrm{~min}$. The absorbance of solution in each tube was detected with UV-9100 ultraviolet spectrophotometer (Beijing Persee, China) under $550 \mathrm{~nm}$ of wavelength. Standard curve was calculated by setting the concentration as horizontal axis and optical density value as vertical axis. The concentration of SDF and IDF was detected by following the determination of dietary fiber issued by Association of Official Analytical Chemists (Lee et al., 1992; AOAC International, 1996). The animals and the standard diet for mice were supplied by Dossy Experimental Animals Co., Ltd (Chengdu, China). For normalization and the adaptation to the environment, a pre-experiment lasted 7 days was carried out with the same diets using in formal experiment. All of the animals consumed the diets ad libitum and had free access to water as in formal experiment. The formal experiment lasted 21 days. During the whole experimental period, room temperature $\left(25 \pm 1.5^{\circ} \mathrm{C}\right)$ and standard humidity (70\%) were maintained. Mice consumed the diets ad libitum and had free access to water. Feed intake of each mouse was recorded daily. BW of each mouse was recorded every 3 days. At the end of the experiment, all animals were sacrificed. Approximately $4 \mathrm{~g}$ of colonic digesta from each mouse was collected, kept in sterile tubes $(2 \mathrm{ml})$, and immediately frozen at $-80^{\circ} \mathrm{C}$ for genomic DNA extraction and the analysis of bacterial community.

\section{DNA Extraction and Sequencing}

Nucleic acids for each sample was extracted immediately when the animal experiment was finished. A total of 0.04 to $0.06 \mathrm{~g}$ of each colonic digesta sample was weighed for DNA extraction based on the bead-beating method (Zoetendal et al., 1998). The extracted genomic DNA were stored at $-80^{\circ} \mathrm{C}$ until further analysis. PCR amplifications were conducted with the barcoded primer pair 343f/806r set that amplifies the V3-V4 fragments of the 16S rRNA gene (343F: TACGGRAGGCAGCAG, 806R: GGACTACHVGGGTWTCTAAT). The PCR reaction $(25 \mu \mathrm{l})$ system included $10 \mathrm{ng}$ of total DNA, 1 Unit of $1 \times$ Taq buffer (Takara, Japan), $0.2 \mathrm{mM}$ of each $\mathrm{dNTP}$ and $0.4 \mu \mathrm{M}$ of each primer. Amplification condition consisted of an initial denaturation step of $94^{\circ} \mathrm{C}$ for $5 \mathrm{~min}$, followed by 35 cycles of $94^{\circ} \mathrm{C}$ for $30 \mathrm{~s}, 56^{\circ} \mathrm{C}$ for $30 \mathrm{~s}$, and $68^{\circ} \mathrm{C}$ for $45 \mathrm{~s}$ with a final extension at $68^{\circ} \mathrm{C}$ for $5 \mathrm{~min}$. The PCR products (approximately 
$290 \mathrm{bp})$ were separated by electrophoresis in agarose gels (1.5\%, w/v), purified with SanPrep DNA Gel Extraction Kit (Sangon Biotech, Shanghai, China). All PCR products were quantified with Nanodrop 2000 (Thermo Scientific, United States), pooled together with equal molar amount from each sample. The purified library was diluted, denatured, re-diluted, mixed with PhiX (equal to $30 \%$ of final DNA amount) as described in the Illumina library preparation protocols, and then applied to an Illumina Miseq system for sequencing. The sequences with high quality (max-length $<571 \mathrm{bp}$, min-length $>285 \mathrm{bp}$, average length of the effective sequences reads was $407 \mathrm{bp}$, without ambiguous base ' $N$,' and average base quality score $>30$ ) were used for downstream analysis. A total number of 3,994,666 of V3-V4 16S rRNA valid sequences reads were obtained from 28 samples, with an average of 88,770 effective sequences reads for each sample (the minimum of one sample was 45,242 and the maximum was 122,647). All reads were deposited in the National Center for Biotechnology Information (NCBI) and can be accessed in the Short Read Archive (SRA) under accession number SRP065932.

\section{Bioinformatics Analysis}

Pairs of reads from the original DNA fragments were merged by using FLASH (Magoč and Salzberg, 2011) (Fast Length Adjustment of SHort reads), a very fast and accurate software tool which is designed to merge pairs of reads when the original DNA fragments are shorter than twice the length of reads. Sequencing reads was assigned to each sample according to the unique barcode of each sample. Chimeric sequences were removed using USEARCH based on the UCHIME algorithm (Edgar et al., 2011). The microbial diversity was analyzed using Quantitative Insights Into Microbial Ecology (QIIME) software (Caporaso et al., 2010) with Python scripts. Operational taxonomic units (OTUs) were picked using the de novo OTU picking protocol with a $97 \%$ similarity threshold. Alpha diversity was estimated based on Shannon index, Chaol and number of observed species. Jack knifed beta diversity included both unweighted and weighted Unifrac distances calculated with 10 times subsampling, and distances were visualized by PcoA (Lozupone and Knight, 2005), and the separation was tested using $\mathrm{R}$ in Anosim. Taxonomic assignment of OTUs was performed by comparing sequences to the Greengenes database (gg_13_5_otus).

Mann-Whitney $U$-test was used to test for significant differences in alpha diversity, and two-sided Student's $t$-test was used to test for significant differences in beta diversity between sample groups. Linear discriminant analysis coupled with effect size (LEfSe) was performed to identify bacterial taxa differentially represented between groups at genus or higher taxonomy levels (Segata et al., 2011). The functional profiles of microbial communities were predicted by using PICRUSt (Langille et al., 2013). Bootstrap Mann-Whitney U-test with 1,000 per mutations was also used to identify gene pathways or OTUs with significantly different abundance among groups. The R packages 'Phyloseq,' 'biom,' 'pheatmap' were used for data analysis and plotting (McDonald et al., 2012; McMurdie and Holmes, 2013).

\section{Real-Time PCR Analysis of Bacterial Groups}

The copy numbers of Firmicutes (Guo et al., 2008), Bacteroidetes (Guo et al., 2008), Desulfovibrio desulfuricans (Rinttilä et al., 2004), Enterobacteriaceae family (Bartosch et al., 2004), $\gamma$ Proteobacteria (De Gregoris et al., 2011), $\beta$-Proteobacteria (Fierer et al., 2005), Ruminococcaceae (Garcia-Mazcorro et al., 2012), Prevotella (Larsen et al., 2010), Methanogens (Denman et al., 2007), and sulfate reducing bacteria (SRB) (Kondo et al., 2004) in the colonic samples were quantified by real-time PCR on an Bio-Rad CFX-96 real time system (Bio-Rad, United States) using SYBR Green as the fluorescent dye. The primers and program of real-time PCR reaction for each bacteria was followed as the methods mentioned in the references displayed above. A reaction mixture $(25 \mu \mathrm{l})$ consisted of $12.5 \mu \mathrm{l}$ of IQ SYBR Green Supermix (Bio-Rad, United States), $0.2 \mu \mathrm{M}$ of each primer set and $5 \mu \mathrm{l}$ of the template DNA. The amount of DNA in each sample was determined in triplicate, and the mean values were calculated. To generate the standard curve for each bacterial group, the amplicons of corresponding endpoint PCR reaction performed on genomic DNA with the group-specific primer sets were first quantified (NanoDrop 2000, United States) and purified (Cloning Enhancer Kit, TaKaRa, Japan), and then serially diluted to be used as templates to generate the corresponding standard curve.

\section{Detection of SCFAs Concentrations}

The concentrations of main SCFAs (acetate, propionate and buyterate) in the colonic digesta samples were determined using a gas chromatograph (GC) (GC-14B, Shimadzu, Japan; Capillary Column: $30 \mathrm{~m} \times 0.32 \mathrm{~mm} \times 0.25 \mu \mathrm{m}$ film thickness) (Franklin et al., 2002). A total of 1 gram of digesta sample was thawed and suspended in $2 \mathrm{ml}$ of distilled water and vortexed. Each sample was centrifuged $(12,000 \mathrm{~g})$ at $4^{\circ} \mathrm{C}$ for $10 \mathrm{~min}$. The supernatant $(1 \mathrm{ml})$ was then transferred into a 2 -ml centrifuge tube and mixed with $0.2 \mathrm{ml}$ metaphosphoric acid, and $1 \mu \mathrm{l}$ of the supernatant was analyzed using the GC with a flame ionization detector and an oven temperature of $100-150^{\circ} \mathrm{C}\left(\mathrm{N}_{2}\right.$ as the carrier gas at $1.8 \mathrm{ml} / \mathrm{min}$ ). The minimal measminimal detectable limit for each SCFA was $0.1 \mathrm{mmol} / \mathrm{l}$ (Luo et al., 2015).

\section{Statistical Analysis}

Differences in the relative abundance of certain bacterial phyla or genera, average feed intake, BW gain, the numbers of bacterial groups and the concentrations of SCFAs among treatments were analyzed with one-way ANOVA using the statistical software SPSS 16.0. Differences were considered significant when $p<0.05$.

\section{RESULTS}

\section{Feed Intake, Body Weight Gain of Mice and SCFAs Concentrations of Digesta Samples in Different Groups}

The differences of average weight gain (AWG) of mice in the four groups were only found before day 12 (Table 1 and Supplementary Figure S1). In the first period (1-3 days), the 
AWG of mice in group $\mathrm{G}$ showed significantly lower than group $\mathrm{C}$ and $\mathrm{M}(p<0.05)$. From days 4 to 6 , the AWG of mice in group $M$ was significantly lower than group GM $(p<0.05)$. From days 7 to 9, the AWG of mice in group G was observed significantly higher than group C and GM $(p<0.05)$. From days 10 to 12 , the AWG of mice in group G showed significantly higher than group $\mathrm{C}$ and $\mathrm{M}(p<0.05)$, while no significant differences were found in AWG of mice in the four groups from days 1 to $21(p>0.05)$. The differences of average feed intake (ADFI) of mice in the four groups were observed during the whole experiment (Table 1 and Supplementary Figure S1A). The difference of ADFI of mice in the four groups in each period was also showed in Table 1. For whole period (1-21 days), the ADFI showed significantly different among the four groups ( $p<0.001$, Table 1 and Supplementary Figure S1B).

The concentration of acetate and butyrate and the ratio of acetate to propionate showed no difference among the four groups $(p>0.05)$, while the concentration of propionate was significantly higher in group G and GM compared to group C and $\mathrm{M}(p<0.05$, Table 2$)$.

\section{Metadata and Sequence Analysis}

After assigning OTU and chimera checking, sequencing for 28 samples yielded 2,296,025 sequences with an average of $82,001 \pm 13,719$ sequences per sample. All reads were assigned to 4,368 non-singleton OTUs, which could be assigned to a total of 25 bacterial phyla and 275 bacterial genera. Each sample had $753 \pm 205$ OTUs on average (Supplementary Table S2).

\section{The Microbial Diversity in the Colonic Samples of Different Treatments}

Three alpha diversity measures were calculated including Shannon's diversity index, observed species (observed OTUs), and Chaol (estimated number of OTUs). The Shannon index of group $\mathrm{G}$ was significantly lower than that of the control and $\mathrm{M}$ groups ( $p<0.01$, Figure 1A). Observed and expected bacterial richness were significantly lower in groups $\mathrm{G}$ and $\mathrm{GM}$ than those of the control and M groups ( $p<0.01$, Figures 1B,C).

\section{Composition of Bacterial Communities in the Colonic Digesta of Mice in Different Groups}

A total of 25 phyla were detected in the colonic digesta of the experimental mice. Of these 25, six phyla (Actinobacteria, Bacteroidetes, Deferribacteres, Firmicutes, Proteobacteria, and Tenericutes) were the most predominant, each comprising more than $0.1 \%$ of the total reads per group (Table 3 and Supplementary Figure S2). The relative abundance of bacteria from the phyla Bacteroidetes and Firmicutes was significantly different between groups $(p<0.001)$. The relative abundance of bacteria from the phylum Bacteroidetes in group $G$ was significantly higher than that in the control, M and GM groups $(p<0.01)$, whereas its relative abundance $(12.9 \pm 4.2 \%)$ was lowest in the control group and significantly lower than that in groups M and GM ( $p=0.025,0.020$, respectively) (Table 3$)$. The relative abundance of bacteria from the phylum Firmicutes was highest in the control group $(80.1 \pm 4.8 \%)$. In contrast, relative abundance of Firmicutes was significantly lower in group G

TABLE 1 | Average daily feed intake (ADFI) and average weight gain (AWG) of mice in the four different treatments.

\begin{tabular}{|c|c|c|c|c|c|c|c|c|}
\hline & Group & 1-3 days & 4-6 days & 7-9 days & $10-12$ days & $13-16$ days & 17-21 days & 1-21 days \\
\hline \multirow[t]{5}{*}{ AWG g } & C & $1.36 \pm 0.52^{a}$ & $0.73 \pm 0.55^{a b}$ & $-0.07 \pm 0.35^{b}$ & $-0.60 \pm 0.35^{b}$ & $1.19 \pm 0.24$ & $-0.41 \pm 0.35$ & $2.19 \pm 0.75$ \\
\hline & $G$ & $-0.56 \pm 0.56^{b}$ & $0.36 \pm 0.64^{a b}$ & $1.20 \pm 0.43^{a}$ & $0.84 \pm 0.31^{a}$ & $0.90 \pm 0.38$ & $-0.37 \pm 0.32$ & $2.37 \pm 0.32$ \\
\hline & $M$ & $1.81 \pm 0.24^{a}$ & $-0.53 \pm 0.44^{b}$ & $0.34 \pm 0.47^{a b}$ & $-0.60 \pm 0.56^{b}$ & $1.17 \pm 0.73$ & $-0.79 \pm 0.55$ & $1.41 \pm 0.62$ \\
\hline & GM & $0.84 \pm 0.57^{a b}$ & $1.53 \pm 0.68^{a}$ & $-0.29 \pm 0.23^{b}$ & $0.61 \pm 0.35^{a b}$ & $0.34 \pm 0.28$ & $-1.04 \pm 0.47$ & $2.00 \pm 0.65$ \\
\hline & $P$-value & 0.014 & 0.123 & 0.053 & 0.027 & 0.503 & 0.655 & 0.705 \\
\hline \multirow[t]{5}{*}{ ADFI $g / d$} & C & $6.03 \pm 0.57^{a}$ & $5.89 \pm 0.40^{a}$ & $3.70 \pm 0.26^{a}$ & $4.49 \pm 0.41^{a}$ & $5.90 \pm 0.21^{a}$ & $5.51 \pm 0.44^{a}$ & $5.33 \pm 0.18^{a}$ \\
\hline & $G$ & $2.74 \pm 0.40^{c}$ & $3.68 \pm 0.42^{c}$ & $3.03 \pm 0.19^{b}$ & $3.72 \pm 0.22^{a b}$ & $3.41 \pm 0.24^{c}$ & $3.18 \pm 0.28^{b}$ & $3.42 \pm 0.12^{c}$ \\
\hline & $M$ & $4.61 \pm 0.31^{b}$ & $5.04 \pm 0.51^{\mathrm{ab}}$ & $3.31 \pm 0.20^{a b}$ & $3.52 \pm 0.25^{b}$ & $4.51 \pm 0.39^{b}$ & $5.71 \pm 0.25^{a}$ & $4.63 \pm 0.18^{b}$ \\
\hline & GM & $3.71 \pm 0.48^{b c}$ & $4.50 \pm 0.36^{b c}$ & $3.10 \pm 0.17^{a b}$ & $3.57 \pm 0.17^{b}$ & $4.89 \pm 0.19^{b}$ & $4.77 \pm 0.37^{a}$ & $4.19 \pm 0.30^{b}$ \\
\hline & $P$-value & 0.000 & 0.009 & 0.117 & 0.074 & 0.000 & 0.000 & 0.001 \\
\hline
\end{tabular}

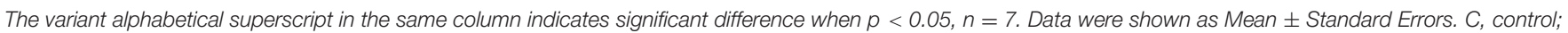
G, glucan; M, MCC; GM, glucan and MCC.

TABLE 2 | Concentrations of acetate, butyrate and propionate in the colonic digesta of mice in the four groups.

\begin{tabular}{|c|c|c|c|c|c|}
\hline Item & C & G & $\mathbf{M}$ & GM & $P$-value \\
\hline Acetate $\mu \mathrm{mol} / \mathrm{g}$ & $17.72 \pm 4.35$ & $29.28 \pm 13.65$ & $17.18 \pm 6.75$ & $27.01 \pm 13.35$ & 0.096 \\
\hline Propionate $\mu \mathrm{mol} / \mathrm{g}$ & $2.64 \pm 1.02^{b}$ & $4.61 \pm 2.41^{a}$ & $2.32 \pm 0.67^{b}$ & $4.51 \pm 1.50^{\mathrm{a}}$ & 0.019 \\
\hline Butyrate $\mu \mathrm{mol} / \mathrm{g}$ & $1.41 \pm 0.98$ & $0.77 \pm 0.55$ & $2.03 \pm 2.27$ & $1.02 \pm 0.47$ & 0.328 \\
\hline Acetate/Propionate & $7.13 \pm 1.62$ & $6.51 \pm 1.57$ & $7.47 \pm 2.52$ & $6.35 \pm 3.05$ & 0.784 \\
\hline
\end{tabular}

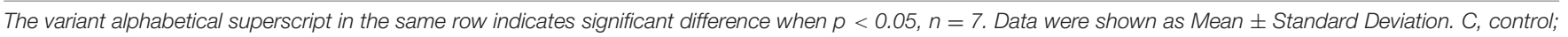
G, glucan; M, MCC; GM, glucan and MCC. 

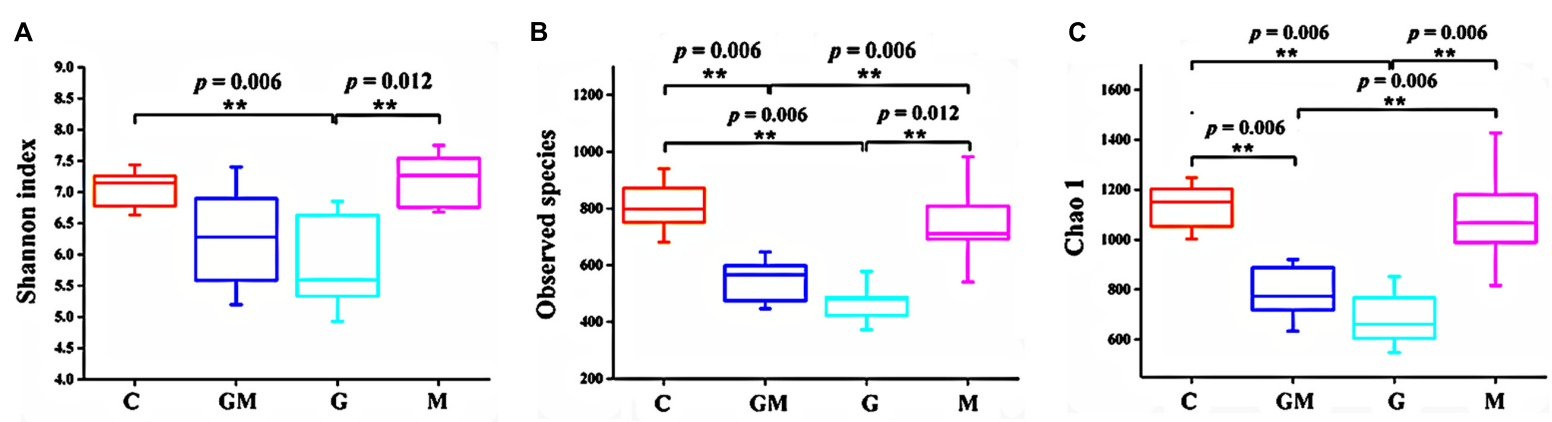

FIGURE 1 | Differences on bacterial community diversity and richness among the four treatments. (A) Shannon index; (B) Observed OTUs; (C) Chao1 index. Differences were considered significant when $p<0.05,{ }^{*} p<0.05,{ }^{* *} p<0.01$. C, control; G, glucan; M, MCC; GM, glucan and MCC.

TABLE 3 | Relative abundance (\%) of main bacterial phyla (more than $0.1 \%$ ) in the colon of mice in different treatments.

\begin{tabular}{|c|c|c|c|c|c|}
\hline Phylum & C & G & $\mathbf{M}$ & GM & $P$-value \\
\hline Actinobacteria & $0.12 \pm 0.06$ & $0.23 \pm 0.23$ & $0.20 \pm 0.23$ & $0.10 \pm 0.08$ & 0.41 \\
\hline Bacteroidetes** & $12.93 \pm 4.18$ & $55.41 \pm 15.70$ & $29.36 \pm 14.72$ & $30.07 \pm 13.38$ & 0.00 \\
\hline Deferribacteres & $1.23 \pm 0.88$ & $0.23 \pm 0.21$ & $0.75 \pm 1.20$ & $1.32 \pm 1.47$ & 0.22 \\
\hline Firmicutes** & $80.09 \pm 4.77$ & $38.69 \pm 14.78$ & $64.10 \pm 13.33$ & $62.35 \pm 15.50$ & 0.00 \\
\hline Proteobacteria & $5.08 \pm 1.72$ & $4.92 \pm 2.67$ & $5.10 \pm 1.61$ & $5.33 \pm 2.89$ & 0.99 \\
\hline Tenericutes & $0.35 \pm 0.29$ & $0.27 \pm 0.57$ & $0.18 \pm 0.19$ & $0.63 \pm 1.55$ & 0.77 \\
\hline
\end{tabular}

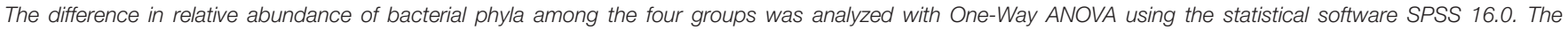

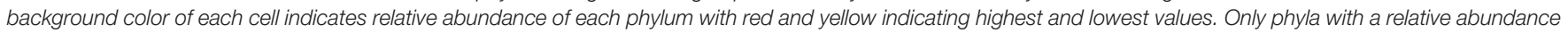

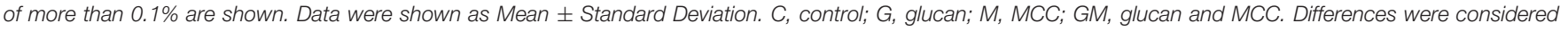
significant when $p<0.05, * * p<0.01$.

$(38.7 \pm 14.8 \%)$, than that in groups M and GM $(p=0.001,0.002$, respectively) (Figure 2, Table 3, and Supplementary Figure S3). In addition to the two predominant phyla, Proteobacteria was observed as the third most predominant phylum in the colonic samples of the all four groups with no significant differences between groups $(p>0.05)$. All five classes of Proteobacteria (Alpha-, Beta-, Delta-, Epsilon-, and Gamma-proteobacteria) were found in all of the samples. Relative abundance of Betaproteobacteria and Gammaproteobacteria from samples in group $G$ was significantly higher than that in the control, $M$ and GM groups $(p=0.015,0.005,0.037$ and $0.023,0.034$, 0.018, respectively) (Supplementary Figure S4), while relative abundance of Deltaproteobacteria in group G was significantly lower than that in the other groups $(p=0.013,0.002,0.044$, respectively) (Supplementary Figure S4). At the family level, the relative abundance of the Enterobacteriaceae was significantly higher in group $\mathrm{G}$ than in the other three groups $(p \leq 0.016)$.

Linear discriminant analysis (LDA) and LDA coupled with effect size (LefSe) showed that a total of 53 bacterial taxa were different in relative abundance $(\alpha=0.01$, LDA score $>3.0)$ among the four groups (Figure 3 and Supplementary Figure S5). A total of 17 taxa were significantly more abundant in group $\mathrm{G}$ than in the other groups (e.g., Bacteroides spp., Dehalobacterium spp., Prevotella spp., $p<0.05), 14$ taxa were significantly more abundant in group M (e.g., Adlercreutzia spp., Odoribacter spp., Coprococcus spp., AF12, $p<0.05), 18$ taxa were significantly more abundant in the control group (e.g., Rikenella spp., $p<0.05$ ), while only four taxa were significantly more abundant in the GM group (e.g., Oscillospira spp., Desulfovibrio spp., Ruminoccaceae, $p<0.05$ ) (Figure 3 and Supplementary Figures S3, S6). From these 53 taxa, those had a relative abundance of at least $0.01 \%$ and occurred in at least one of the treatments were further tested using analysis of variance (ANOVA) (Supplementary Table S3).

\section{Core Colonic Bacterial Communities of Mice in Different Treatments}

The relationships among the colonic bacterial community structures of the four groups were examined by using Principal Coordinates Analysis (PCoA) based on an unweighted UniFrac distance matrix (Figure 4), indicating that there was no significant separation of colonical microbiome between the control and group M, whereas the control and GM group, control and $\mathrm{G}$ group, and groups $\mathrm{M}$ and $\mathrm{G}$ can be significantly separated ( $R=0.379, p=0.001$, Supplementary Figure S7).

The core bacterial community for each treatment was analyzed based on the data from the seven individuals in the treatment, and was defined as those taxa found in 90\% of the colonic samples for each treatment. For group $G$ and the controls, the core community consisted of 11 OTUs, and the reads of the core OTUs comprised as much as 96.6 and $95.4 \%$ of the total community, respectively. For groups GM and $\mathrm{M}, 10$ and 14 OTUs were found, respectively, as the core bacterial community, and the core community comprised 96.9 and $95.4 \%$ of the total community, respectively. Within the core bacterial community, Bacteroides (41.7\%), Oscillospira 


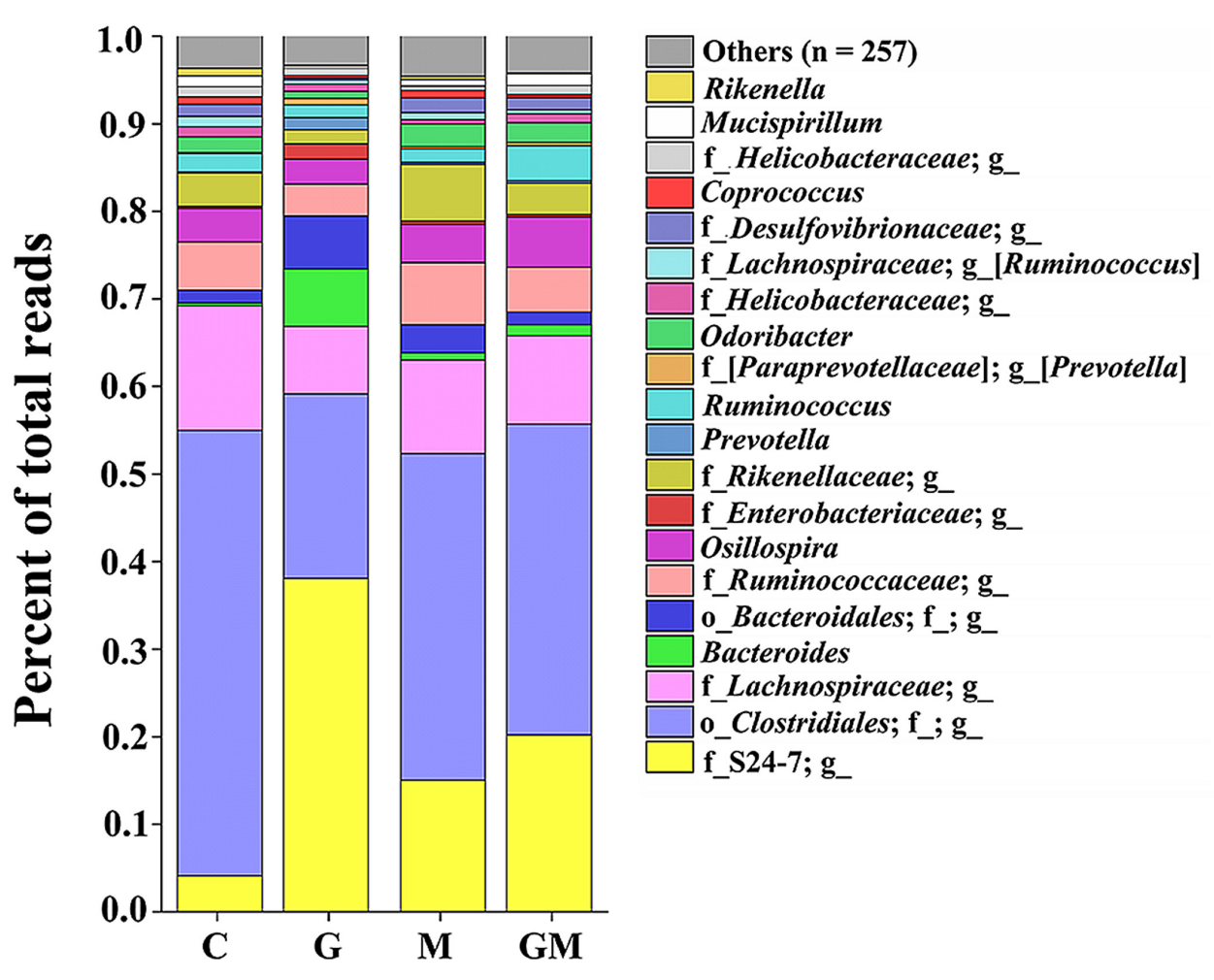

FIGURE 2 | Bacterial composition in the colonic digesta of mice from the four treatments. Each bar represents the average relative abundance of each bacterial taxon within a group. The top 20 most abundant taxa are shown. These taxa were observed with high relative abundance in the four groups, and comprise a relative abundance ranging from 95.4 to $96.7 \%$. g, genus level; f, family level, o, order level. The underline followed by no annotation means no known taxonomic level was classified. C, control; G, glucan; M, MCC; GM, glucan and MCC.

(19.9\%), Prevotella (10.7\%), and Ruminococcus (10.0\%) were identified as the four most predominant genera in the colon of mice fed the glucan-diet. These four genera comprised approximately $82.3 \%$ of the core community (Figure 5). For mice fed the MCC-diet, Oscillospira (39.7\%), Ruminococcus (13.6\%), Desulfovibrio (11.1\%), Coprococcus (7.5\%), and Bacteroides (7.1\%) were the top five genera, comprising $79.0 \%$ of the bacterial community. The genera Oscillospira (35.2\%), Ruminococcus (26.4\%), Desulfovibrio (8.9\%), Bacteroides (8.0\%), and Flexispira (6.2\%) comprised the main core of bacteria in the colon of mice fed with the mixed (GM) diet, accounting for $84.7 \%$ of the core microbiota (Figure 5). Oscillospira (32.7\%), Ruminococcus (18.8\%), Flexispira (10.2\%), Desulfovibrio (8.6\%), Coprococcus (7.4\%), and Rikenella (6.8\%) were the six dominant genera in the colonic samples of the control group, and comprised approximately $84.5 \%$ of the total core community (Figure 5).

\section{Quantification of Specific Bacterial Groups in the Four Treatments Using Q-PCR}

As shown in Table 4, the numbers of Enterobacteriaceae, Prevotella, and $\beta$-Proteobacteria in the colonic samples from group $\mathrm{G}$ were significantly higher than other groups $(p<0.05)$, while the number of Ruminococcaceae of group $G$ showed significantly lower than others $(p<0.01)$. The copy number of $D$. desulfuricans showed lowest in samples from group $G$ and highest in those from group GM $(p<0.01)$. The quantity of Bacteroidetes from group $G$ were significantly higher than the control group $(p=0.01)$, while the number of Firmicutes were significantly higher in the controls than in the other groups $(p<0.01)$. The number of $\gamma$-Proteobacteria in group $\mathrm{G}$ was significantly higher than the $M$ and control groups $(p<0.05)$. For the two main hydrogenotrophic bacteria, the copy number of SRB in group G was significantly lower than the other groups with a significantly higher number in the GM and M groups than the control group $(p<0.01)$, while no significant difference on the number of methanogens was found among the four groups $(p>0.05)$.

\section{Predicted Functional Composition of Colonic Microbial Communities of Mice in Different Treatments}

To investigate alterations in colonic microbial function, the software program Phylogenetic Investigation of Communities by Reconstruction of Unobserved States (PICRUSt) was applied to the 16S rRNA gene sequencing data. PICRUSt results were then analyzed using LEfSe to identify microbial functions that were significantly different in their relative abundance among groups. 

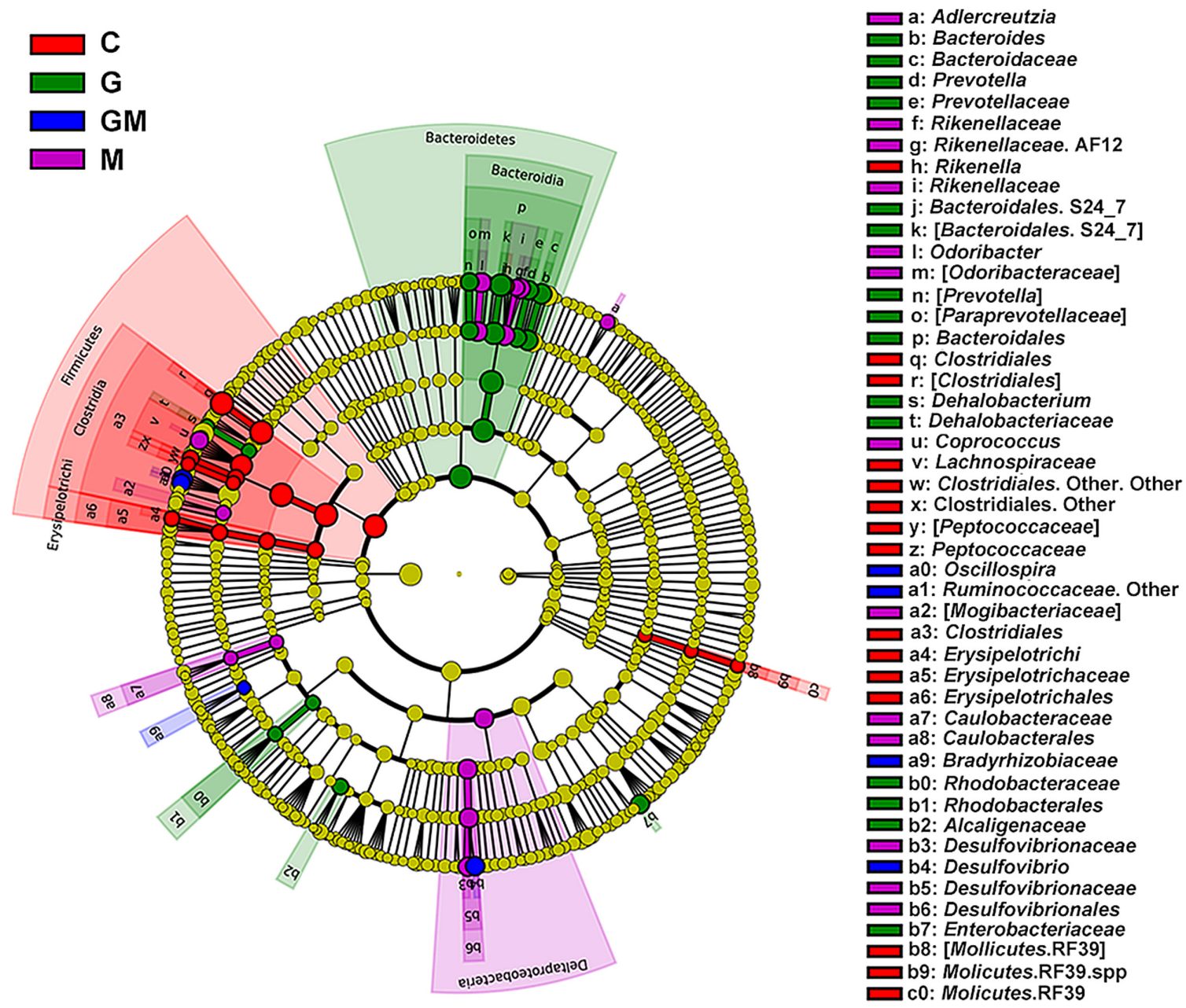

FIGURE 3 | Histogram of the linear discriminant analysis (LDA) scores computed for bacterial taxa differentially abundant among the four groups using default parameters. Six levels of the biomarkers (from phylum to genus) were shown in this figure. The circles radiating from inner to outside mean levels from phylum to genus. Small spots on each circle mean sub-classifications on the corresponding level, and the size of each spot is in proportion to the corresponding sub-classification. Sub-classifications with no differences among the treatments are colored with yellow, while biomarkers in each treatment are colored with different colors. A total of 53 differentially abundant bacterial taxa were detected. Of those, 17 taxa were significantly overrepresented in the colon of mice fed with oat-derived $\beta$-glucan (green), 14 taxa were overrepresented in mice fed with MCC (purple), 4 taxa were overrepresented in mice fed the mixture of the two fibers (blue), and 14 taxa were overrepresented in controlled mice (red). C, control; G, glucan; M, MCC; GM, glucan and MCC.

Of the 248 KEGG (Kyoto Encyclopedia of Genes and Genomes) pathways, a total of 15 differentially abundant bacterial functions were observed especially between the control and group $G$ ( $\alpha=0.01$, LDA score $>3.0$ ) (Figure 6). Of those, three pathways on energy and carbohydrate metabolism (e.g., "Oxidative phosphorylation" and "Tricarboxylic acid cycle"), two pathways on genetic information processing (e.g., "Ribosome"), and one pathway on "Membrane and cellular structural molecules" were overrepresented in glucan-fed mice (Figure 6).

\section{DISCUSSION}

The health benefits of dietary fiber have long been appreciated. Dietary fiber has been shown to protect against development of diseases, including diabetes, cardiovascular disease, colon cancer, and obesity (Slavin, 1987; Roberfroid et al., 2010). Recent studies indicate a link between intake of dietary fibers and colonic bacterial communities in animals and humans (Chassard et al., 2010; De Filippo et al., 2010; Isken et al., 2010). However, the effect of different types of dietary fibers, especially fermentable SDF and IDF, on colonic microbial community composition and associated functions, was often ignored. Thus, in the present study, we investigated bacterial community composition using sequencing of PCR-amplified 16S rRNA gene fragments and further predicted associated microbial functions in the colon of $\mathrm{BALB} / \mathrm{c}$ mice fed with diets supplemented with either oat-derived $\beta$-glucan, MCC, or the mixture of both fibers. Moreover, the changes on the relative abundance of bacteria were confirmed by the qPCR results. 


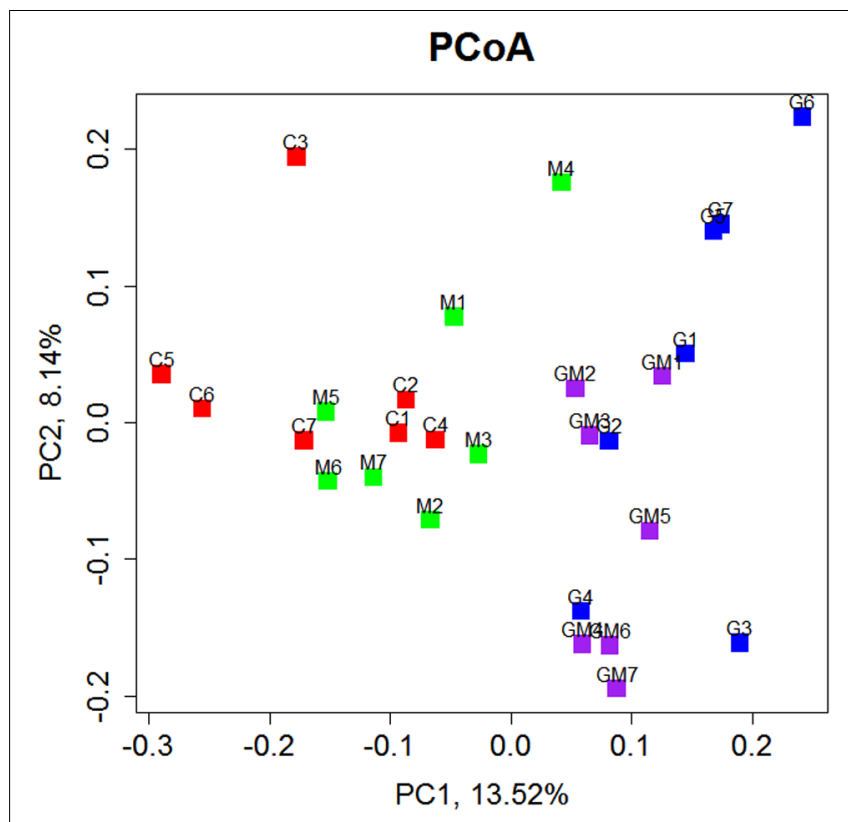

FIGURE 4 | Principal Coordinate Analysis (PCoA) of bacterial community structures of the colonic microbiota of four experimental groups, each represented by one color. $\mathrm{PCoA}$ shows distinct bacterial communities for the four different treatments ( $p=0.001)$. C, control; G, glucan; M, MCC; GM, glucan and MCC.

In the current study, the decrease of ADFI of mice fed with $\beta$-glucan enriched diet was probably associated with the gelforming properties (Isken et al., 2010) of SDF and increased distention (Slavin, 2013). Study on humanized mice showed that diet, such as fiber-containing diet can modify GI transit, which then affects the composition of the microbial community (Kashyap et al., 2013; Roager et al., 2016). On the other hand, the higher feed intake has been proved to increase the length of the intestine of mice (Selman et al., 2001), while the ingestion of high ratio of dietary carbohydrates may not have this affect (Shibuya et al., 2015). According to our result, the ADFI of mice in control group showed a highest intake, which may suggest a longer intestine and rapid gut throughput of this group, and in turn, affect the microbial community. As the length of intestine and transit time of the mice was not investigated in current study, further study will be needed to verify this speculation. Although the ADFI of the mice fed with glucan-containing diet was lowest for the whole experimental period, the AWG of the mice showed increased from day 7, which elicited the similar AWG between groups at the end of the experiment. This may be related to the remarkable increase of propionate in the colon of mice in group G. In some non-ruminant (Verbrugghe et al., 2012) animal and ruminants (Zhang et al., 2016), gut microbe-produced propionate can be absorbed and used by host as one of the main substrates of gluconeogenesis. A large amount of propionate production is commonly observed during the fermentation of soluble complex carbohydrates (Stevens and Hume, 1998; German et al., 2015). Although the increase of acetate in the colonic digesta of mice in group G and GM was not remarkable due to the larger individual differences (a larger sample size may have led to significant differences), the concentration of acetate in the samples in these two groups showed a substantial improvement. Acetate produced by gut microbes is one of the energy source of host (Kimura et al., 2016) as propionate, the observed higher concentration of propionate and acetate in these mice might be directly utilized by the intestinal epithelial cells as energy source of host, which needs to be further verified with highly sensitive method such as metabolomics analysis or under a larger sample size.

The $\alpha$ diversity index of colonic bacteria was significantly decreased in animals fed diet $\mathrm{G}$ as compared to animals fed the control diet, while the bacterial diversity in mice fed the MCC diet was not different from those given the control diet, which was also confirmed by the PCoA plot. No decrease was found in animals fed with diet $\mathrm{M}$, whereas the mixed diet, containing lower amounts of both fibers, also led to a reduced diversity, albeit slightly less pronounced than for diet G. Although only one representative fiber per type was investigated in the present study, it is tempting to speculate based on our findings that the supplement of SDF, such as oat-derived $\beta$-glucan, but not IDF, may reduce the biodiversity of colonic microorganisms of mice. A study on rats showed that compared to non-nutritive cellulosefed rats (56 and $56.8 \mathrm{~g} / \mathrm{kg}$ diet), supplementation of high-viscosity $\beta$-glucan in the diet increased the bacterial diversity in the cecum of rats as measured by denaturing gradient gel electrophoresis (DGGE) of 16S rRNA gene fragments (Snart et al., 2006). This was not confirmed by the present study, however, this difference may be due to the high proportion of fibers (approximately $20 \%$ in each diet) in the present study.

The relationships among the colonic bacterial community structures of the four groups were examined by using PCoA based on an unweighted UniFrac distance matrix (Figure 4), indicating that there was no significant separation of colonical microbiome between the control and group $\mathrm{M}$, while the control and GM group, control and $G$ group, and groups $M$ and $G$ can be significantly separated ( $p=0.001$ ). At the phylum level, Firmicutes and Bacteroidetes were found as the most predominant taxa in all colonic samples, which is consistent with previous studies in humans and mice (Bäckhed et al., 2005; Tremaroli and Bäckhed, 2012; Yatsunenko et al., 2012). In the present study, the relative abundance of Bacteroidetes was remarkably increased in the colon of mice fed with high concentrations of $\beta$-glucan, whereas the addition of MCC led to a decrease in relative abundance of this phylum (Supplementary Figure S3). It has been reported that a diet reduced in fermentable carbohydrates decreased the relative abundance of representatives from the phylum Firmicutes (Belcheva et al., 2014). However, only the Firmicutes/Bacteroidetes ratio of the control group was significantly higher than other groups $(p \leq 0.01)$. The difference of Firmicutes/Bacteroidetes between group $\mathrm{G}(p=0.078)$ and $\mathrm{M}(p=0.067)$ was nearly significant. Our findings suggest that although the microbial community in the distal gut may be altered by dietary fiber, probably some SDF like oat-derived $\beta$-glucan, but not IDF such as MCC, might have primary impact on the community structure.

Proteobacteria is also a major phylum in the gut of animals. In the present study, although no change was found at the 


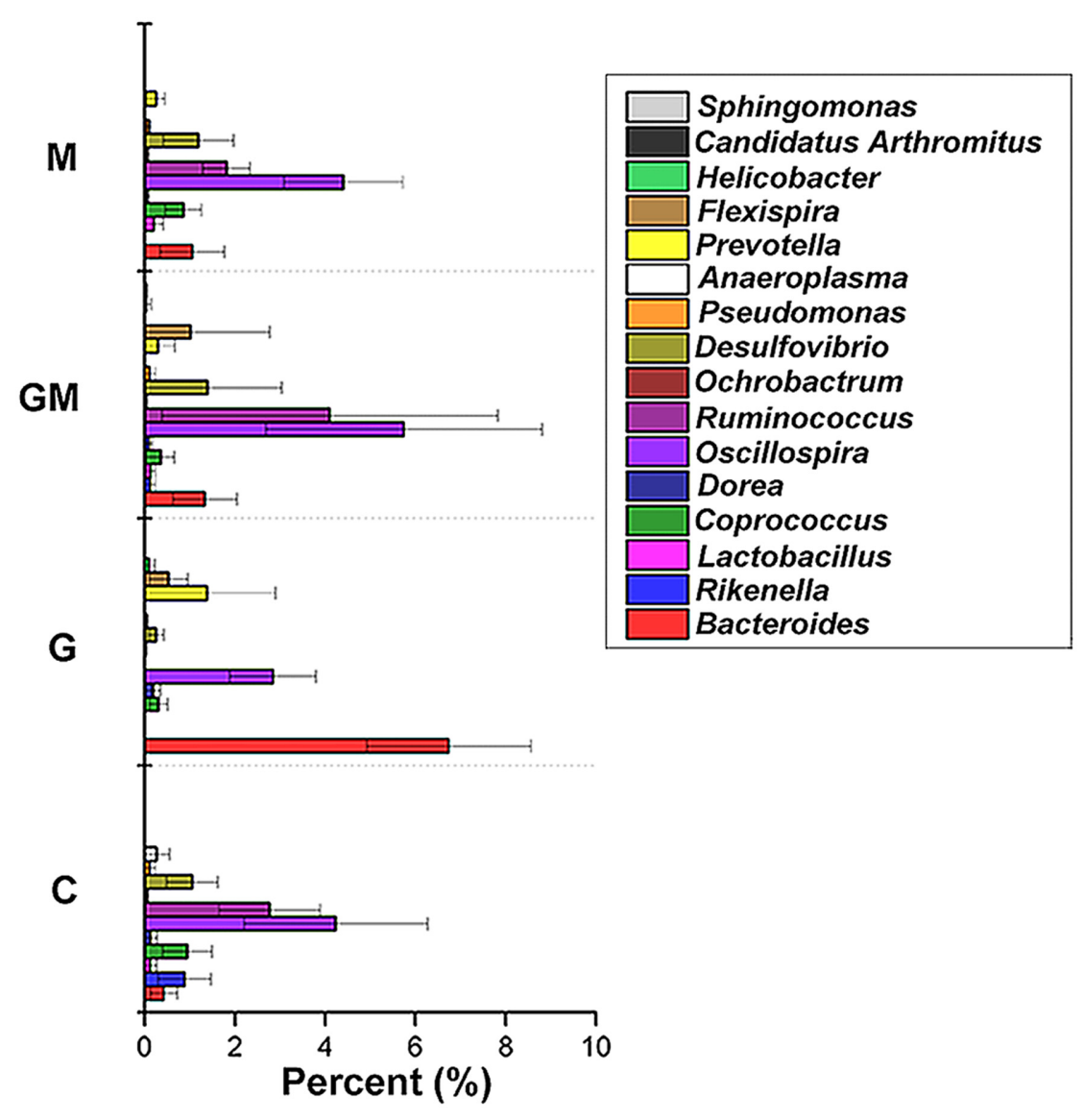

FIGURE 5 | Core bacterial genera in the colon of mice in the four different groups. To test for evidence of a core bacterial community in the colonic samples, the compute_core_microbiome function within QIIME was used, requiring the core OTUs to be present in at least $90 \%$ of the samples as based on the non-rarefied data set. C, control; G, glucan; M, MCC; GM, glucan and MCC.

TABLE 4 | The quantity of certain bacterial groups in the colonic digesta from mice in the four treatments [log ${ }_{10}$ (copy numbers of gene)/gram of wet sample].

\begin{tabular}{|c|c|c|c|c|c|}
\hline Bacteria & C & G & $\mathbf{M}$ & GM & $P$-value \\
\hline Firmicutes & $11.80 \pm 0.37^{a}$ & $10.80 \pm 0.42^{b}$ & $11.06 \pm 0.31^{\mathrm{bc}}$ & $11.22 \pm 0.36^{c}$ & 0.00 \\
\hline Ruminococcaceae & $10.46 \pm 0.74^{a}$ & $9.43 \pm 0.73^{b}$ & $10.53 \pm 0.42^{a}$ & $10.86 \pm 0.33^{a}$ & 0.00 \\
\hline Bacteroidetes & $10.11 \pm 0.55^{a}$ & $11.12 \pm 0.56^{b}$ & $10.58 \pm 0.54^{\mathrm{ab}}$ & $10.57 \pm 0.33^{\mathrm{ab}}$ & 0.01 \\
\hline Prevotella & $5.93 \pm 0.53^{a}$ & $6.54 \pm 0.39^{b}$ & $5.95 \pm 0.32^{\mathrm{a}}$ & $6.04 \pm 0.23^{a}$ & 0.02 \\
\hline$\beta$-Proteobacteria & $6.74 \pm 0.20^{a}$ & $8.04 \pm 0.47^{b}$ & $7.05 \pm 0.42^{a}$ & $7.03 \pm 0.44^{a}$ & 0.00 \\
\hline$\gamma$-Proteobacteria & $9.15 \pm 0.62^{a}$ & $10.13 \pm 0.41^{b}$ & $9.30 \pm 0.88^{a}$ & $9.70 \pm 0.62^{\mathrm{ab}}$ & 0.04 \\
\hline Enterobacteriaceae & $7.04 \pm 0.26^{a}$ & $8.53 \pm 0.71^{b}$ & $7.43 \pm 0.24^{a}$ & $7.23 \pm 0.22^{a}$ & 0.00 \\
\hline SRB & $8.07 \pm 0.49^{a}$ & $7.25 \pm 0.36^{b}$ & $9.05 \pm 0.35^{\mathrm{c}}$ & $8.61 \pm 0.37^{c}$ & 0.00 \\
\hline Desulfovibrio desulfuricans & $8.12 \pm 0.35^{a}$ & $6.60 \pm 0.27^{b}$ & $8.20 \pm 0.20^{a}$ & $8.59 \pm 0.21^{c}$ & 0.00 \\
\hline Methanogens & $6.93 \pm 0.21$ & $6.98 \pm 0.34$ & $6.91 \pm 0.30$ & $6.90 \pm 0.23$ & 0.95 \\
\hline
\end{tabular}

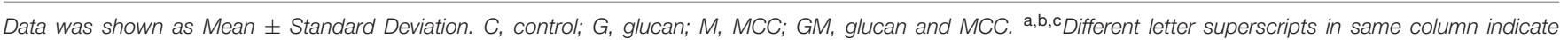
significant difference $(p<0.05)$.

phylum level, the relative abundance of bacteria from the three classes of Proteobacteria were significantly changed in mice, fed with glucan-supplemented diet, but the trends were not consistent. The relative abundance of Betaproteobacteria, Gammaproteobacteria, and family Enterobacteriaceae within the Gammaproteobacteria was increased with the present of dietary $\beta$-glucan (SDF) (Supplementary Figure S4). Gut bacteria belonging to the Beta-and Gammaproteobacteria generally include the majority of potential pathogens (Hernandez-Doria and Sperandio, 2013; Cariveau et al., 2014), while the family 

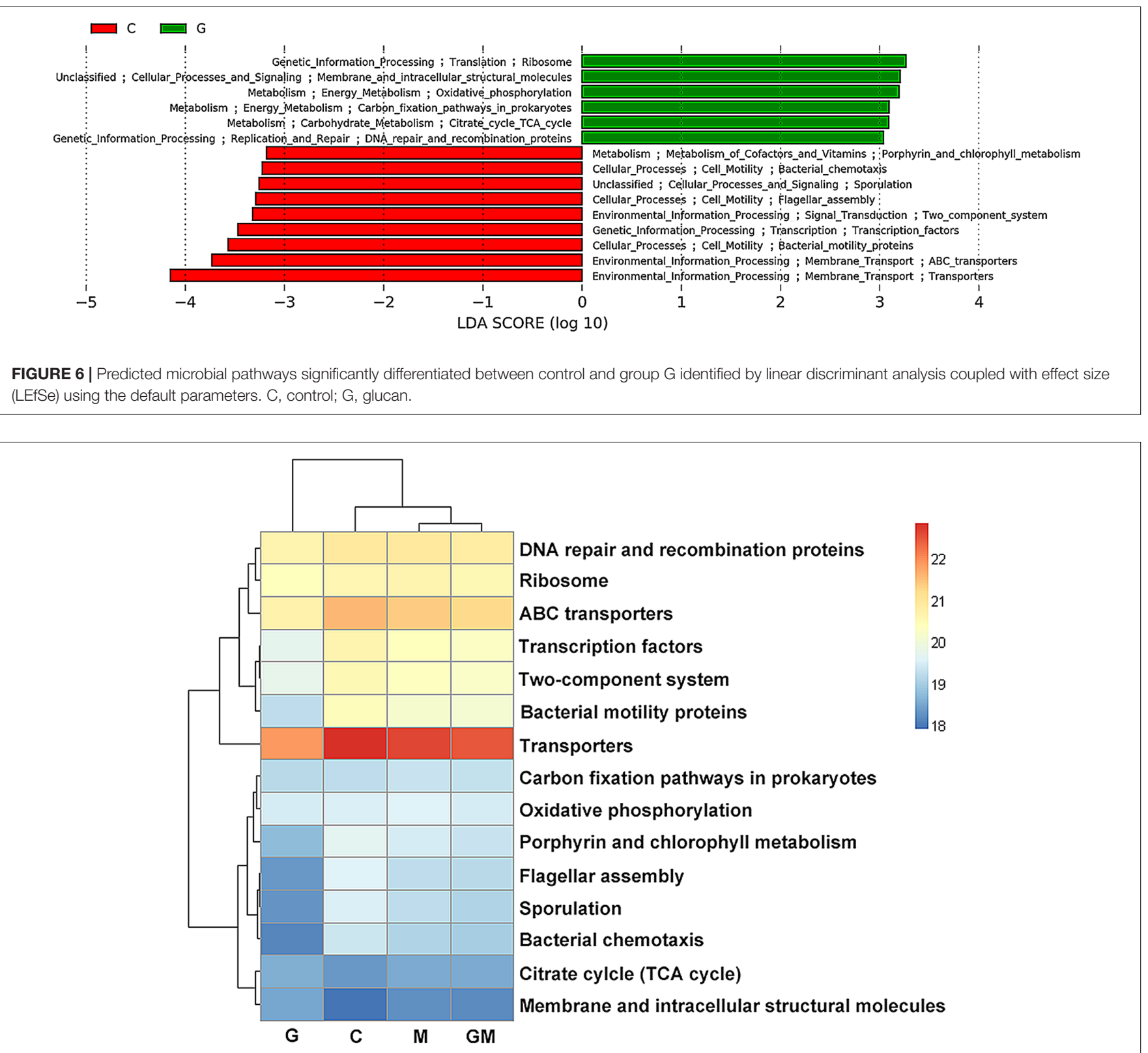

FIGURE 7 | Predicted function of colonic microbiota among mice in the four treatments. The gene copy numbers of samples within the same sample group were pooled. Values of each functional gene (row) were log10 transformed. All of the three levels of KEGG pathways are shown in the heatmap. Significance of differences in gene distribution among groups was tested using bootstrap Mann-Whitney U-test with cutoffs of $p<0.01$, FDR $<0.1$, Mean counts $>10$. Genes with significance of differences among groups from 0.01 to 0.05 were not shown. C, control; G, glucan; M, MCC; GM, glucan and MCC.

Enterobacteriaceae contains Gram-negative bacteria including harmless symbionts and pathogens, such as Escherichia coli, Salmonella, and Yersinia pestis (Stecher et al., 2012). In the current study, when dietary $\beta$-glucan was increased, potential pathogens such as those in the Enterobacteriaceae increased, which was further confirmed by real-time PCR results. We also found that the relative abundance of bacteria belonging to the Deltaproteobacteria was decreased with the increase of IDF/SDF ratio (Supplementary Figure S4). A large number of bacteria in the Deltaproteobacteria are affiliated to the SRB (Rodionov et al., 2004; Sorokin et al., 2008), a cluster of hydrogenotrophs (Vianna et al., 2008) that can improve the fermentation efficiency of gut microorganisms by removing end products such as $\mathrm{H}_{2}$. MCC-degrading species were shown to produce high amounts of $\mathrm{H}_{2}$ from cellulose fermentation (Chassard et al., 2010). In addition, $\mathrm{H}_{2}$ is needed to produce propionate by certain bacteria (Hosseini et al., 2011), but the concentration of propionate was only found remarkably increased in the samples of mice fed with glucan-containing diet with a lowest quantity of SRB, which suggests that the producing of propionate but not SRB 
might be one of the ways to remove $\mathrm{H}_{2}$ by colonic bacteria of these mice. One of the main sulfate reducing product by SRB is $\mathrm{H}_{2} \mathrm{~S}$ which is generally recognized as a signaling molecule mediating gastrointestinal secretion and intestinal peristalsis, and also associated with the inflammatory reaction of intestine (Farrugia and Szurszewski, 2014). However, as the production of $\mathrm{H}_{2} \mathrm{~S}$ and $\mathrm{H}_{2}$ is very hard to monitor in vivo in mice, whether the increase of SRB was harmful or not to the gut health of mice cannot be confirmed in current study. According to realtime PCR results, the number of SRB was remarkably higher in groups $\mathrm{M}$ and GM. Considering there was no change on the methanogens, the change of SRB found in the current study may indicate that SRB were the preferred hydrogen utilizers, rather than methanogens, in the colon of mice consuming the MCC diet. However, this assumption needs to be verified by further studies.

The core microbial community was unique in mice from group G. Both Bacteroides and Prevotella spp. were found in group G, and both are able to degrade diverse plant polysaccharides, most of which are fermentable fibers and native cellulose (Chassard et al., 2010). However, cellulolytic enzymes have not yet been characterized from any human Bacteroides strain (Flint et al., 2012). Bacteria affiliated to Bacteroides spp. were also observed as a core genus in the colon of mice fed with MCC, and the glucan and MCC mixed-diet, presented lower relative abundances, whereas Bacteroides spp. were predominant in G-diet fed mice. This suggests these bacteria play an important role during the degradation of oat $\beta$-glucan. Prevotella spp. have been shown to utilize fermentable complex carbohydrates (Ivarsson et al., 2014). In people who consume more carbohydrates, especially fiber, Prevotella spp. Dominate (Wu et al., 2011), making up 53\% of the gut bacteria of African children (De Filippo et al., 2010). In the present study, Prevotella was only observed as a core genus in group $\mathrm{G}$ mice, which confirms the studies mentioned above. However, Prevotella are also implicated in TMAO formation from meat carnitines, thereby exacerbating the cardiovascular outcomes of red meat consumption (Koeth et al., 2013). Notably, Flexispira spp., initially isolated from aborted sheep fetuses (Kirkbride et al., 1985), and formerly recognized as a genus associated with human chronic diarrhea (Archer et al., 1988), was found as a core genus in mice from the group $G$ and GM.

Members of the acetogenic genus Dehalobacterium were found in samples from glucan-fed mice. In contrast, nonor moderate-acetogens and hydrogen-producing bacteria, such as Adlercreutzia spp. (Maruo et al., 2008), Odoribacter spp. (Nagai et al., 2010) and Coprococcus spp. (Patel et al., 1981) were found in samples from MCC-fed mice. This further confirmed that the increase of SRB in mice from groups $M$ and GM might probably be associated with the production of $\mathrm{H}_{2}$ during the fermentation of MCC. In addition, bacteria with strong fiber-degradation capability, such as bacteria in the family Ruminoccaceae, which are well known to degrade SDF, but also IDF, with their multiple carbohydrate active enzymes (CAZy) (Flint et al., 2012), were found in samples from mice fed with glucan and MCC-mixture. This further suggests a potential specialization in ecological niches or guilds in the hindgut of mice consuming different types of dietary fibers. The predicted functional analysis further confirms this proposition.

With respect to metabolic pathways, the enrichment of "Energy metabolism" and "Carbohydrate metabolism" pathways in glucan-fed mice are remarkable, indicating a high activity on carbohydrate utilization of bacteria in the colon of these mice. $\beta$-glucan has been proved as a SDF with high fermentability (Andersson et al., 2004). The supplement of oat derived $\beta$-glucan may directly improve the ability of polysaccharides degradation of colonic bacteria. This functional change is consistent with the increase of SDF degrading bacteria mentioned above, such as Bacteroides and Prevotella spp. Interestingly, the enrichment of these two types of pathways in samples from group $M$ and GM were also found in current study (Figure 7), although compared with control group, the change was not significant. Our result suggests that both of SDF and IDF may increase the capability of polysaccharide utilization of colonic bacteria in mice, with a larger influence of SDF.

In summary, the high level (approximately 20\%) supplement of oat-derived $\beta$-glucan into diet, rather than MCC or their mixture, remarkably decreased the bacterial $\alpha$-diversity in the colon of BALB/c mice in current study. The colonic bacteria can specifically response to different types of dietary fibers, and different core bacterial species were found in the colon of mice fed with corresponding fibers. The altered bacterial community in the colon of mice with the two dietary fibers resulted in a more efficient degradation of dietary polysaccharides, which was further confirmed by the enrichment of "Energy metabolism" and "Carbohydrate metabolism" pathways in these mice. The higher concentration of colonic propionate in mice fed glucan-containing diet may be associated with the lowest ADFI and highest AWG of these mice. Although dietary $\beta$-glucan increased the relative abundance of potential pathogens belonging to Proteobacteria, such as Betaproteobacteria, Gammaproteobacteria (including Enterobacteriaceae) and Deltaproteobacteria, no significant change was found on the concentration of acetate and butyrate in the colonic digesta of these mice. Co-supplementation of the two fibers may be more beneficial to increase the diversity of colonic bacteria and reduce the conditional pathogens.

\section{AUTHOR CONTRIBUTIONS}

YL designed the experiment, wrote the paper, and had primary responsibility for the final content. LZ conducted the animal trial and data analysis. HL conducted the data analysis of sequencing. A-DW and HS helped to analyze the data and write the paper. KZ, XD, QZ, SB, and JW helped to conduct the animal trial and sample collection. JL prepared the feed and helped to conduct the animal trial. PZ, GT, JC, and DC helped to design the experiment. All authors read and approved the final manuscript. 


\section{FUNDING}

The work presented in this manuscript was supported by the Natural Science Foundation of China (grant number 31301987).

\section{REFERENCES}

Andersson, A. A., Armö, E., Grangeon, E., Fredriksson, H., Andersson, R., and Åman, P. (2004). Molecular weight and structure units of $(1 \rightarrow 3,1 \rightarrow 4)$ $\beta$-glucans in dough and bread made from hull-less barley milling fractions. J. Cereal Sci. 40, 195-204. doi: 10.1016/j.jcs.2004.07.001

AOAC International (ed.) (1996). Official Methods of Analysis of AOAC International, Vol. II, 16th Edn. Arlingtonm, VA: Association of Official Analytical Chemists International.

Archer, J. R., Romero, S., Ritchie, A., Hamacher, M., Steiner, B., Bryner, J., et al. (1988). Characterization of an unclassified microaerophilic bacterium associated with gastroenteritis. J. Clin. Microbiol. 26, 101-105.

Arumugam, M., Raes, J., Pelletier, E., Le Paslier, D., Yamada, T., Mende, D. R., et al. (2011). Enterotypes of the human gut microbiome. Nature 473, 174-180. doi: 10.1038/nature09944

Bäckhed, F., Ding, H., Wang, T., Hooper, L. V., Koh, G. Y., Nagy, A., et al. (2004). The gut microbiota as an environmental factor that regulates fat storage. Proc. Natl. Acad. Sci. U.S.A. 101, 15718-15723. doi: 10.1073/pnas.0407076101

Bäckhed, F., Ley, R. E., Sonnenburg, J. L., Peterson, D. A., and Gordon, J. I. (2005). Host-bacterial mutualism in the human intestine. Science 307, 1915-1920. doi: 10.1126/science. 1104816

Bartosch, S., Fite, A., Macfarlane, G. T., and McMurdo, M. E. (2004). Characterization of bacterial communities in feces from healthy elderly volunteers and hospitalized elderly patients by using real-time PCR and effects of antibiotic treatment on the fecal microbiota. Appl. Environ. Microbiol. 70, 3575-3581. doi: 10.1128/AEM.70.6.3575-3581.2004

Bauer, M. W., Driskill, L. E., Callen, W., Snead, M. A., Mathur, E. J., and Kelly, R. M. (1999). An endoglucanase, EglA, from the hyperthermophilic ArchaeonPyrococcus furiosus hydrolyzes $\beta-1,4$ bonds in mixed-linkage $(1 \rightarrow 3)$, $(1 \rightarrow 4)$ - $\beta$-D-glucans and cellulose. J. Bacteriol. 181, 284-290.

Belcheva, A., Irrazabal, T., Robertson, S. J., Streutker, C., Maughan, H., Rubino, S., et al. (2014). Gut microbial metabolism drives transformation of msh2deficient colon epithelial cells. Cell 158, 288-299. doi: 10.1016/j.cell.2014. 04.051

Caporaso, J. G., Kuczynski, J., Stombaugh, J., Bittinger, K., Bushman, F. D., Costello, E. K., et al. (2010). QIIME allows analysis of high-throughput community sequencing data. Nat. Methods 7, 335-336. doi: 10.1038/nmeth. f.303

Cariveau, D. P., Powell, J. E., Koch, H., Winfree, R., and Moran, N. A. (2014). Variation in gut microbial communities and its association with pathogen infection in wild bumble bees (Bombus). ISME J. 8, 2369-2379. doi: 10.1038/ ismej. 2014.68

Chassard, C., Delmas, E., Robert, C., and Bernalier-Donadille, A. (2010). The cellulose-degrading microbial community of the human gut varies according to the presence or absence of methanogens. FEMS Microbiol. Ecol. 74, 205-213. doi: 10.1111/j.1574-6941.2010.00941.x

Cummings, J., and Macfarlane, G. (1991). The control and consequences of bacterial fermentation in the human colon. J. Appl. Bacteriol. 70, 443-459. doi: 10.1111/j.1365-2672.1991.tb02739.x

David, L. A., Maurice, C. F., Carmody, R. N., Gootenberg, D. B., Button, J. E., Wolfe, B. E., et al. (2014). Diet rapidly and reproducibly alters the human gut microbiome. Nature 505, 559-563. doi: 10.1038/nature12820

De Filippo, C., Cavalieri, D., Di Paola, M., Ramazzotti, M., Poullet, J. B., Massart, S., et al. (2010). Impact of diet in shaping gut microbiota revealed by a comparative study in children from Europe and rural Africa. Proc. Natl. Acad. Sci. U.S.A. 107, 14691-14696. doi: 10.1073/pnas.1005963107

De Gregoris, T. B., Aldred, N., Clare, A. S., and Burgess, J. G. (2011). Improvement of phylum- and class-specific primers for real-time PCR quantification of bacterial taxa. J. Microbiol. Methods 86, 351-356. doi: 10.1016/j.mimet.2011. 06.010

\section{SUPPLEMENTARY MATERIAL}

The Supplementary Material for this article can be found online at: http://journal.frontiersin.org/article/10.3389/fmicb. 2017.00966/full\#supplementary-material

Denman, S. E., Tomkins, N. W., and McSweeney, C. S. (2007). Quantitation and diversity analysis of ruminal methanogenic populations in response to the antimethanogenic compound bromochloromethane. FEMS Microbiol. Ecol. 62, 313-322. doi: 10.1111/j.1574-6941.2007.00394.x

Devkota, S., Wang, Y., Musch, M. W., Leone, V., Fehlner-Peach, H., Nadimpalli, A., et al. (2012). Dietary-fat-induced taurocholic acid promotes pathobiont expansion and colitis in $I l 10^{-/-}$mice. Nature 487, 104-108. doi: 10.1038/ nature 11225

Duncan, S. H., Russell, W. R., Quartieri, A., Rossi, M., Parkhill, J., Walker, A. W., et al. (2016). Wheat bran promotes enrichment within the human colonic microbiota of butyrate-producing bacteria that release ferulic acid. Environ. Microbiol. 18, 2214-2225. doi: 10.1111/1462-2920.13158

Edgar, R. C., Haas, B. J., Clemente, J. C., Quince, C., and Knight, R. (2011). UCHIME improves sensitivity and speed of chimera detection. Bioinformatics 27, 2194-2200. doi: 10.1093/bioinformatics/btr381

El Aidy, S., Derrien, M., Merrifield, C. A., Levenez, F., Doré, J., Boekschoten, M. V., et al. (2013). Gut bacteria-host metabolic interplay during conventionalisation of the mouse germfree colon. ISME J. 7, 743-755. doi: 10.1038/ismej. 2012.142

Farrugia, G., and Szurszewski, J. H. (2014). Carbon monoxide, hydrogen sulfide, and nitric oxide as signaling molecules in the gastrointestinal tract. Gastroenterology 147, 303-313. doi: 10.1053/j.gastro.2014.04.041

Fierer, N., Jackson, J. A., Vilgalys, R., and Jackson, R. B. (2005). Assessment of soil microbial community structure by use of taxon-specific quantitative PCR assays. Appl. Environ. Microbiol. 71, 4117-4120. doi: 10.1128/AEM.71.7.41174120.2005

Flint, H. J., Scott, K. P., Duncan, S. H., Louis, P., and Forano, E. (2012). Microbial degradation of complex carbohydrates in the gut. Gut Microbes 3, 289-306. doi: 10.4161/gmic.19897

Franklin, M., Mathew, A., Vickers, J., and Clift, R. (2002). Characterization of microbial populations and volatile fatty acid concentrations in the jejunum, ileum, and cecum of pigs weaned at 17 vs 24 days of age. J. Anim. Sci. 80, 2904-2910.

Garcia-Mazcorro, J. F., Suchodolski, J. S., Jones, K. R., Clark-Price, S. C., Dowd, S. E., Minamoto, Y., et al. (2012). Effect of the proton pump inhibitor omeprazole on the gastrointestinal bacterial microbiota of healthy dogs. FEMS Microbiol. Ecol. 80, 624-636. doi: 10.1111/j.1574-6941.2012.01331.x

German, D. P., Sung, A., Jhaveri, P., and Agnihotri, R. (2015). More than one way to be an herbivore: convergent evolution of herbivory using different digestive strategies in prickleback fishes (Stichaeidae). Zoology 118, 161-170. doi: 10.1016/j.zool.2014.12.002

Gibson, G. R., Scott, K. P., Rastall, R. A., Tuohy, K. M., Hotchkiss, A., DubertFerrandon, A., et al. (2010). Dietary prebiotics: current status and new definition. Food Sci. Technol. Bull. Funct. Foods 7, 1-19. doi: 10.1616/14762137.15880

Guo, X., Xia, X., Tang, R., Zhou, J., Zhao, H., and Wang, K. (2008). Development of a real-time PCR method for Firmicutes and Bacteroidetes in faeces and its application to quantify intestinal population of obese and lean pigs. Lett. Appl. Microbiol. 47, 367-373. doi: 10.1111/j.1472-765X.2008.02408.x

Hernandez-Doria, J. D., and Sperandio, V. (2013). Nutrient and chemical sensing by intestinal pathogens. Microbes Infect. 15, 759-764. doi: 10.1016/j.micinf. 2013.06.013

Hooper, L. V., Littman, D. R., and Macpherson, A. J. (2012). Interactions between the microbiota and the immune system. Science 336, 1268-1273. doi: 10.1126/ science. 1223490

Hosseini, E., Grootaert, C., Verstraete, W., and Van de Wiele, T. (2011). Propionate as a health-promoting microbial metabolite in the human gut. Nutr. Rev. 69, 245-258. doi: 10.1111/j.1753-4887.2011.00388.x

Isken, F., Klaus, S., Osterhoff, M., Pfeiffer, A. F., and Weickert, M. O. (2010). Effects of long-term soluble vs. insoluble dietary fiber intake on high-fat diet-induced 
obesity in C57BL/6J mice. J. Nutr. Biochem. 21, 278-284. doi: 10.1016/j.jnutbio. 2008.12.012

Ivarsson, E., Roos, S., Liu, H., and Lindberg, J. (2014). Fermentable nonstarch polysaccharides increases the abundance of Bacteroides-PrevotellaPorphyromonas in ileal microbial community of growing pigs. Animal 8, 1777-1787. doi: 10.1017/S1751731114001827

Jensen, T., Kiersgaard, M., Sørensen, D. B., and Mikkelsen, L. (2013). Fasting of mice: a review. Lab. Anim. 47, 225-240. doi: 10.1177/0023677213501659

Kashyap, P. C., Marcobal, A., Ursell, L. K., Larauche, M., Duboc, H., Earle, K. A., et al. (2013). Complex interactions among diet, gastrointestinal transit, and gut microbiota in humanized mice. Gastroenterology 144, 967-977. doi: 10.1053/j. gastro.2013.01.047

Kau, A. L., Ahern, P. P., Griffin, N. W., Goodman, A. L., and Gordon, J. I. (2011). Human nutrition, the gut microbiome and the immune system. Nature 474, 327-336. doi: 10.1038/nature10213

Kimura, I., Inoue, D., Hirano, K., and Tsujimoto, G. (2016). "The SCFA receptor GPR43 and energy metabolism," in Obesity and Diabetes: Energy Regulation by Free Fatty Acid Receptors, Vol. 3, eds I. Kimura and A. Ichimura (Lausanne: Frontiers Media SA), 7.

Kirkbride, C., Gates, C., Collins, J., and Ritchie, A. (1985). Ovine abortion associated with an anaerobic bacterium. J. Am. Vet. Med. Assoc. 186, 789-791.

Koeth, R. A., Wang, Z., Levison, B. S., Buffa, J. A., Org, E., Sheehy, B. T., et al. (2013). Intestinal microbiota metabolism of L-carnitine, a nutrient in red meat, promotes atherosclerosis. Nat. Med. 19, 576-585. doi: 10.1038/nm.3145

Kondo, R., Nedwell, D. B., Purdy, K. J., and Silva, S. Q. (2004). Detection and enumeration of sulphate-reducing bacteria in estuarine sediments by competitive PCR. Geomicrobiol. J. 21, 145-157. doi: 10.1080/ 01490450490275307

Langille, M. G., Zaneveld, J., Caporaso, J. G., McDonald, D., Knights, D., Reyes, J. A., et al. (2013). Predictive functional profiling of microbial communities using 16S rRNA marker gene sequences. Nat. Biotechnol. 31, 814-821. doi: $10.1038 /$ nbt. 2676

Larsen, N., Vogensen, F. K., van den Berg, F. W., Nielsen, D. S., Andreasen, A. S., Pedersen, B. K., et al. (2010). Gut microbiota in human adults with type 2 diabetes differs from non-diabetic adults. PLoS ONE 5:e9085. doi: 10.1371/ journal.pone. 0009085

Lattimer, J. M., and Haub, M. D. (2010). Effects of dietary fiber and its components on metabolic health. Nutrients 2, 1266-1289. doi: 10.3390/nu2121266

Lee, S. C., Prosky, L., and De Vries, J. (1992). Determination of total, soluble, and insoluble dietary fiber in foods: enzymatic-gravimetric method, MES-TRIS buffer: collaborative study. J AOAC Int. 75, 395-416.

Liu, T.-W., Cephas, K. D., Holscher, H. D., Kerr, K. R., Mangian, H. F., Tappenden, K. A., et al. (2016). Nondigestible fructans alter gastrointestinal barrier function, gene expression, histomorphology, and the microbiota profiles of diet-induced obese C57BL/6J mice. J. Nutr. 146, 949-956. doi: 10.3945/jn.115. 227504

Lozupone, C., and Knight, R. (2005). UniFrac: a new phylogenetic method for comparing microbial communities. Appl. Environ. Microbiol. 71, 8228-8235. doi: 10.1128/AEM.71.12.8228-8235.2005

Luo, Y.-H., Yang, C., Wright, A.-D. G., He, J., and Chen, D.-W. (2015). Responses in ileal and cecal bacteria to low and high amylose/amylopectin ratio diets in growing pigs. Appl. Microbiol. Biotechnol. 99, 10627-10638. doi: 10.1007/ s00253-015-6917-2

Magoč, T., and Salzberg, S. L. (2011). FLASH: fast length adjustment of short reads to improve genome assemblies. Bioinformatics 27, 2957-2963. doi: 10.1093/ bioinformatics/btr507

Marlett, J. A., McBurney, M. I., and Slavin, J. L. (2002). Position of the American Dietetic Association: health implications of dietary fiber. J. Am. Diet. Assoc. 102, 993-1000. doi: 10.1016/S0002-8223(02)90228-2

Martinez-Medina, M., Denizot, J., Dreux, N., Robin, F., Billard, E., Bonnet, R., et al. (2014). Western diet induces dysbiosis with increased E coli in CEABAC10 mice, alters host barrier function favouring AIEC colonisation. Gut 63, 116-124. doi: 10.1136/gutjnl-2012-304119

Maruo, T., Sakamoto, M., Ito, C., Toda, T., and Benno, Y. (2008). Adlercreutzia equolifaciens gen. nov., sp. nov., an equol-producing bacterium isolated from human faeces, and emended description of the genus Eggerthella. Int. J. Syst. Evol. Microbiol. 58, 1221-1227. doi: 10.1099/ijs.0.65404-0
McDonald, D., Clemente, J. C., Kuczynski, J., Rideout, J. R., Stombaugh, J., Wendel, D., et al. (2012). The Biological Observation Matrix (BIOM) format or: how I learned to stop worrying and love the ome-ome. GigaScience 1:7. doi: $10.1186 / 2047-217 X-1-7$

McMurdie, P. J., and Holmes, S. (2013). phyloseq: an R package for reproducible interactive analysis and graphics of microbiome census data. PLoS ONE 8:e61217. doi: 10.1371/journal.pone.0061217

Nagai, F., Morotomi, M., Watanabe, Y., Sakon, H., and Tanaka, R. (2010). Alistipes indistinctus sp. nov. and Odoribacter laneus sp. nov., common members of the human intestinal microbiota isolated from faeces. Int. J. Syst. Evol. Microbiol. 60, 1296-1302. doi: 10.1099/ijs.0.014571-0

O'Hara, A. M., and Shanahan, F. (2006). The gut flora as a forgotten organ. EMBO Rep. 7, 688-693. doi: 10.1038/sj.embor.7400731

Pandey, K. (1999). A study of chemical structure of soft and hardwood and wood polymers by FTIR spectroscopy. J. Appl. Polym. Sci. 71, 1969-1975. doi: 10. 1002/(SICI) 1097-4628(19990321)71:12<1969::AID-APP6>3.0.CO;2-D

Patel, T., Jure, K., and Jones, G. (1981). Catabolism of phloroglucinol by the rumen anaerobe Coprococcus. Appl. Environ. Microbiol. 42, 1010-1017.

Relman, D. A. (2012). Microbiology: learning about who we are. Nature 486, 194-195. doi: 10.1038/486194a

Rinttilä, T., Kassinen, A., Malinen, E., Krogius, L., and Palva, A. (2004). Development of an extensive set of $16 \mathrm{~S}$ rDNA-targeted primers for quantification of pathogenic and indigenous bacteria in faecal samples by realtime PCR. J. Appl. Microbiol. 97, 1166-1177. doi: 10.1111/j.1365-2672.2004. 02409.x

Roager, H. M., Hansen, L. B., Bahl, M. I., Frandsen, H. L., Carvalho, V., Gøbel, R. J., et al. (2016). Colonic transit time is related to bacterial metabolism and mucosal turnover in the gut. Nat. Microbiol. 1:16093. doi: 10.1038/nmicrobiol.2016.93

Roberfroid, M., Gibson, G. R., Hoyles, L., McCartney, A. L., Rastall, R., Rowland, I., et al. (2010). Prebiotic effects: metabolic and health benefits. Br. J. Nutr. 104, S1-S63. doi: 10.1017/S0007114510003363

Rodionov, D. A., Dubchak, I., Arkin, A., Alm, E., and Gelfand, M. S. (2004). Reconstruction of regulatory and metabolic pathways in metal-reducing deltaproteobacteria. Genome Biol. 5:R90. doi: 10.1186/gb-2004-5-11-r90

Segata, N., Izard, J., Waldron, L., Gevers, D., Miropolsky, L., Garrett, W. S., et al. (2011). Metagenomic biomarker discovery and explanation. Genome Biol. 12:R60. doi: 10.1186/gb-2011-12-6-r60

Selman, C., Lumsden, S., Bunger, L., Hill, W. G., and Speakman, J. R. (2001). Resting metabolic rate and morphology in mice (Mus musculus) selected for high and low food intake. J. Exp. Biol. 204, 777-784.

Shibuya, T., Kaburagi, T., Nagai, R., and Oshiro, S. (2015). The effects of moderate exercise on secretory IgA production in mice depends on dietary carbohydrate intake. J. Clin. Biochem. Nutr. 57, 44-49. doi: 10.3164/jcbn.15-21

Slavin, J. (1987). Dietary fiber: classification, chemical analyses, and food sources. J. Am. Diet. Assoc. 87, 1164-1171.

Slavin, J. (2013). Fiber and prebiotics: mechanisms and health benefits. Nutrients 5 , 1417-1435. doi: 10.3390/nu5041417

Slavin, J., Savarino, V., Paredes-Diaz, A., and Fotopoulos, G. (2009). A review of the role of soluble fiber in health with specific reference to wheat dextrin. J. Int. Med. Res. 37, 1-17. doi: 10.1177/147323000903700101

Snart, J., Bibiloni, R., Grayson, T., Lay, C., Zhang, H., Allison, G. E., et al. (2006). Supplementation of the diet with high-viscosity beta-glucan results in enrichment for lactobacilli in the rat cecum. Appl. Environ. Microbiol. 72, 1925-1931. doi: 10.1128/AEM.72.3.1925-1931.2006

Sorokin, D. Y., Tourova, T. P., Henstra, A. M., Stams, A. J., Galinski, E. A., and Muyzer, G. (2008). Sulfidogenesis under extremely haloalkaline conditions by Desulfonatronospira thiodismutans gen. nov., sp. nov., and Desulfonatronospira delicata sp. nov.-a novel lineage of Deltaproteobacteria from hypersaline soda lakes. Microbiology 154, 1444-1453. doi: 10.1099/mic.0.2007/015 $628-0$

Stecher, B., Denzler, R., Maier, L., Bernet, F., Sanders, M. J., Pickard, D. J., et al. (2012). Gut inflammation can boost horizontal gene transfer between pathogenic and commensal Enterobacteriaceae. Proc. Natl. Acad. Sci. U.S.A. 109, 1269-1274. doi: 10.1073/pnas.1113246109

Stevens, C. E., and Hume, I. D. (1998). Contributions of microbes in vertebrate gastrointestinal tract to production and conservation of nutrients. Physiol. Rev. $78,393-427$. 
Tremaroli, V., and Bäckhed, F. (2012). Functional interactions between the gut microbiota and host metabolism. Nature 489, 242-249. doi: 10.1038/ nature 11552

Turnbaugh, P. J., Ridaura, V. K., Faith, J. J., Rey, F. E., Knight, R., and Gordon, J. I. (2009). The effect of diet on the human gut microbiome: a metagenomic analysis in humanized gnotobiotic mice. Sci. Transl. Med. 1:6ra14. doi: 10.1126/ scitranslmed.3000322

Verbrugghe, A., Hesta, M., Daminet, S., Polis, I., Holst, J. J., Buyse, J., et al. (2012). Propionate absorbed from the colon acts as gluconeogenic substrate in a strict carnivore, the domestic cat (Felis catus). J. Anim. Physiol. Anim. Nutr. 96, 1054-1064. doi: 10.1111/j.1439-0396.2011.01220.x

Vianna, M., Holtgraewe, S., Seyfarth, I., Conrads, G., and Horz, H. (2008). Quantitative analysis of three hydrogenotrophic microbial groups, methanogenic archaea, sulfate-reducing bacteria, and acetogenic bacteria, within plaque biofilms associated with human periodontal disease. J. Bacteriol. 190, 3779-3785. doi: 10.1128/JB.01861-07

Walker, A. W., Ince, J., Duncan, S. H., Webster, L. M., Holtrop, G., Ze, X., et al. (2011). Dominant and diet-responsive groups of bacteria within the human colonic microbiota. ISME J. 5, 220-230. doi: 10.1038/ismej. 2010.118

Wang, Q., and Ellis, P. R. (2014). Oat $\beta$-glucan: physico-chemical characteristics in relation to its blood-glucose and cholesterol-lowering properties. Br. J. Nutr. 112(Suppl. 2), S4-S13. doi: 10.1017/S00071145140 02256

Wu, G. D., Chen, J., Hoffmann, C., Bittinger, K., Chen, Y.-Y., Keilbaugh, S. A., et al. (2011). Linking long-term dietary patterns with gut microbial enterotypes. Science 334, 105-108. doi: 10.1126/science.1208344
Yang, J., Bindels, L. B., Munoz, R. R. S., Martínez, I., Walter, J., Ramer-Tait, A. E., et al. (2016). Disparate metabolic responses in mice fed a high-fat diet supplemented with maize-derived non-digestible feruloylated oligo-and polysaccharides are linked to changes in the gut microbiota. PLoS ONE 11:e0146144. doi: 10.1371/journal.pone.0146144

Yatsunenko, T., Rey, F. E., Manary, M. J., Trehan, I., Dominguez-Bello, M. G., Contreras, M., et al. (2012). Human gut microbiome viewed across age and geography. Nature 486, 222-227. doi: 10.1038/nature11053

Zhang, Q., Koser, S. L., and Donkin, S. S. (2016). Propionate induces mRNA expression of gluconeogenic genes in bovine calf hepatocytes. J. Dairy Sci. 99, 3908-3915. doi: 10.3168/jds.2015-10312

Zoetendal, E. G., Akkermans, A. D., and De Vos, W. M. (1998). Temperature gradient gel electrophoresis analysis of 16S rRNA from human fecal samples reveals stable and host-specific communities of active bacteria. Appl. Environ. Microbiol. 64, 3854-3859.

Conflict of Interest Statement: The authors declare that the research was conducted in the absence of any commercial or financial relationships that could be construed as a potential conflict of interest.

Copyright (c) 2017 Luo, Zhang, Li, Smidt, Wright, Zhang, Ding, Zeng, Bai, Wang, $L i$, Zheng, Tian, Cai and Chen. This is an open-access article distributed under the terms of the Creative Commons Attribution License (CC BY). The use, distribution or reproduction in other forums is permitted, provided the original author(s) or licensor are credited and that the original publication in this journal is cited, in accordance with accepted academic practice. No use, distribution or reproduction is permitted which does not comply with these terms. 